\title{
On the formation of centreline shrinkage porosity in the continuous casting of steel
}

Michael Vynnycky ${ }^{1 *}$ (D)

\section{"Correspondence:}

michael.vynnycky@ul.ie

${ }^{1}$ Mathematics Applications

Consortium for Science and

Industry (MACSI), Department of

Mathematics and Statistics,

University of Limerick, Limerick, Ireland

\begin{abstract}
A recent asymptotic model for solidification shrinkage-induced macrosegregation in the continuous casting of binary alloys is extended for the purposes of understanding the link between solute segregation and centreline shrinkage porosity, a defect that commonly occurs in the continuous casting of steel. In particular, the analysis elucidates the relationship between microsegregation, mushy-zone permeability, heat transfer and centreline pressure, yielding an inequality that constitutes a criterion for whether or not centreline porosity will form. The possibilities for developing this approach to take account of gas porosity and the implementation of mechanical soft reduction to reduce macrosegregation and shrinkage porosity are also discussed.
\end{abstract}

Keywords: Continuous casting; Porosity; Asymptotic analysis

\section{Introduction}

The formation of porosity in the casting of metals has been the subject of numerous solidification research studies since the 1960s. Piwonka and Flemings [29] and Kubo and Pehlke [18] were the first to identify porosity formation mechanisms and to develop mathematical models to describe porosity evolution, with much of the subsequent work being summarized in reviews by Lee et al. [19] and Stefanescu [35], as well as in the book by Dantzig and Rappaz [6]. However, apart from isolated works by Jacobi and co-workers [15, 41] and, most recently, a thesis by $\mathrm{Du}$ [8], there is little work on porosity formation in the continuous casting of steel, a schematic for which is shown in Fig. 1. This under-researched topic is therefore the focus of this paper.

Porosity in the continuous casting of steel tends to occur at the centreline of a solidified casting, as is demonstrated in Fig. 2, which shows the vertical cross-section, taken through the centreline, of a continuously cast steel sample; the direction of casting was from left to right. In general, the porosity is believed to be caused by three main effects [8]:

- a lack of feeding of melt to compensate for the solidification shrinkage, which is in the interval of $1-7 \%$ for metallic alloys [10];

- the rejection of gas, typically nitrogen, oxygen and hydrogen, from the newly formed solid phase to the surrounding melt, in which it is more soluble;

- solid deformation as a result of tensile stresses, which can also be traced back to a lack of feeding of melt.

(c) The Author(s) 2020. This article is licensed under a Creative Commons Attribution 4.0 International License, which permits use sharing, adaptation, distribution and reproduction in any medium or format, as long as you give appropriate credit to the original author(s) and the source, provide a link to the Creative Commons licence, and indicate if changes were made. The images or other third party material in this article are included in the article's Creative Commons licence, unless indicated otherwise in a credit line to the material. If material is not included in the article's Creative Commons licence and your intended use is not permitted by statutory regulation or exceeds the permitted use, you will need to obtain permission directly from the copyright holder. To view a copy of this licence, visit http://creativecommons.org/licenses/by/4.0/. 


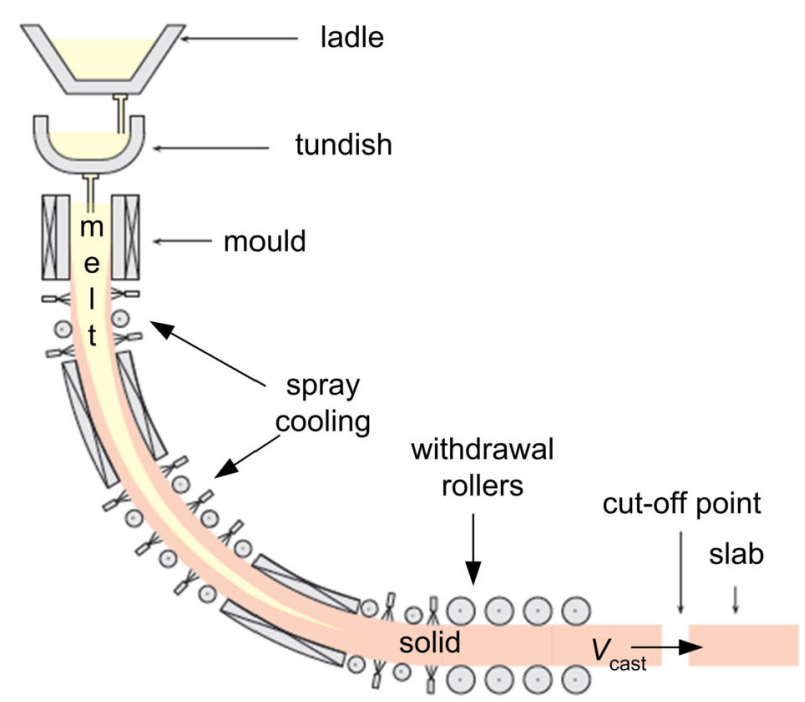

Figure 1 Schematic of the continuous casting process for steel. Melt passes from a ladle to a tundish and then down through a cooled mould region where solidification commences on the mould walls. The partially solidified steel passes through regions of spray cooling and withdrawal rollers, by which point complete solidification has occurred. Throughout, the solidified steel is pulled with a constant speed, $V_{\text {cast }}$

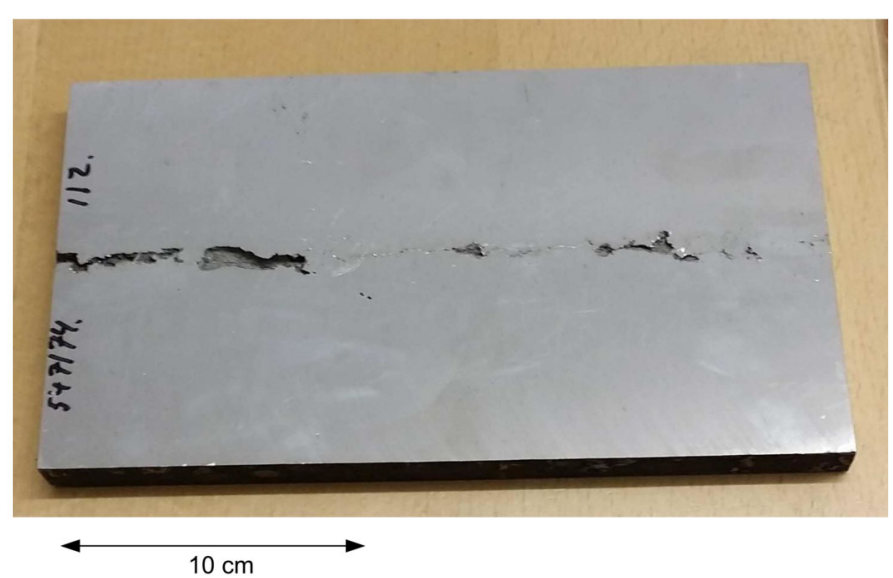

Figure 2 Photograph of a continuous cast steel sample having pores along its centreline. The casting direction was from left to right

In all three cases, when the pressure in the centre decreases below the equilibrium pressure for gas phase, porosity will develop. To focus ideas, here we consider only solidification shrinkage.

Although much attention has been paid to how to model porosity once it forms in a casting process, an alternative activity in this context would be to model how it can be avoided. Indeed, this attitude is consistent with practical attempts to reduce centreline porosity by using the technique of mechanical soft reduction $[7,33,43]$, whereby mild roll tapering is applied; the reduced roll gap squeezes the solid shell towards the centre and thus the solid phase feeds and reduces the porosity level. Moreover, it appears that although solidification shrinkage almost always occurs, shrinkage porosity need not; this 
suggests that there ought to be a criterion that determines what happens as a function of the operating parameters. There do, of course, already exist criteria, the most well-known being the Niyama criterion $[27,28]$, which states that porosity is most likely to form when

$$
\text { G/ } \sqrt{\dot{T}}<\text { constant, }
$$

where $G\left(\mathrm{~K} \mathrm{~cm}^{-1}\right)$ is the thermal gradient and $\dot{T}\left(\mathrm{~K} \mathrm{~min}^{-1}\right)$ is the cooling rate. The constant on the right-hand side of (1.1) depends on the alloy being cast; for the casting of steel, the constant is often taken to be $1\left(\mathrm{~K}^{1 / 2} \mathrm{~min}^{1 / 2} \mathrm{~cm}^{-1}\right)$, with the constant taking different values for other alloys [6]. Another criterion was proposed by Hansen and Sahm [12], who replaced (1.1) by

$$
G /\left[\dot{T}^{1 / 4} v_{l}^{1 / 2}\right]<\text { constant, }
$$

where $v_{l}$ is the flow velocity through the mushy zone. There are also criteria functions that are used to predict where there is a higher probability for a pore to appear [20]; however, these do not represent the physics and are not quantitative tools for calculation of fraction or size of the porosity. According to their derivation, criteria functions only predict the possibility of shrinkage porosity and are highly dependent on the material and casting conditions. Since many experiments need to be done to provide data to find proper constants in the criteria functions, their usage is limited. Furthermore, none of these criteria take into account an actual continuous casting configuration, nor the link that is believed to exist between porosity and solute segregation $[8,10,11]$. In this paper, on the other hand, the goal is to take both of these factors into account by extending a recent asymptotic model for binary-alloy macrosegregation induced by solidification shrinkage [40]; we note in passing that, although modern steels are made with varying combinations of alloy metals to fulfil many purposes, carbon steel-composed simply of iron and carbon-still accounts for around $90 \%$ of steel production [16], making a binary-alloy model a relevant starting point.

The structure of this paper will be the following. In Sect. 2, the governing equations are formulated, whereas in Sect. 3, they are nondimensionalized. In Sect. 4, we analyzed them using asymptotic methods and derive a leading-order problem. Results are presented in Sect. 5, and their consequences are discussed in Sect. 6. Conclusions are drawn in Sect. 7.

\section{Mathematical model}

\subsection{Governing equations}

We consider a steady state two-dimensional (2D) problem, as shown in Fig. 3, in which a molten alloy at temperature $T_{\text {cast }}$ and solute composition $c_{0}$ enters a cooling mould region at $z=0$; if the alloy is carbon steel, the solute is carbon. We will take $T_{\text {cast }}$ to be equal to the liquidus temperature, $T_{\text {liq }}$, at the concentration $c_{0}$; the case when $T_{\text {cast }}>T_{\text {liq }}$ is deferred to future work, as it would complicate the foregoing analysis without adding anything conceptually new. In effect, this means that solidification starts immediately at $z=0$, and hence that there is no melt-only region; consequently, mush begins to form at the inner mould surface at $z=0$, whereas complete solidification occurs slightly further down along the mould wall at $z=z_{\mathrm{s}, \text { init }}$, where $z_{\mathrm{s} \text {,init }}>0$. For simplicity, and in line with many others [8], 


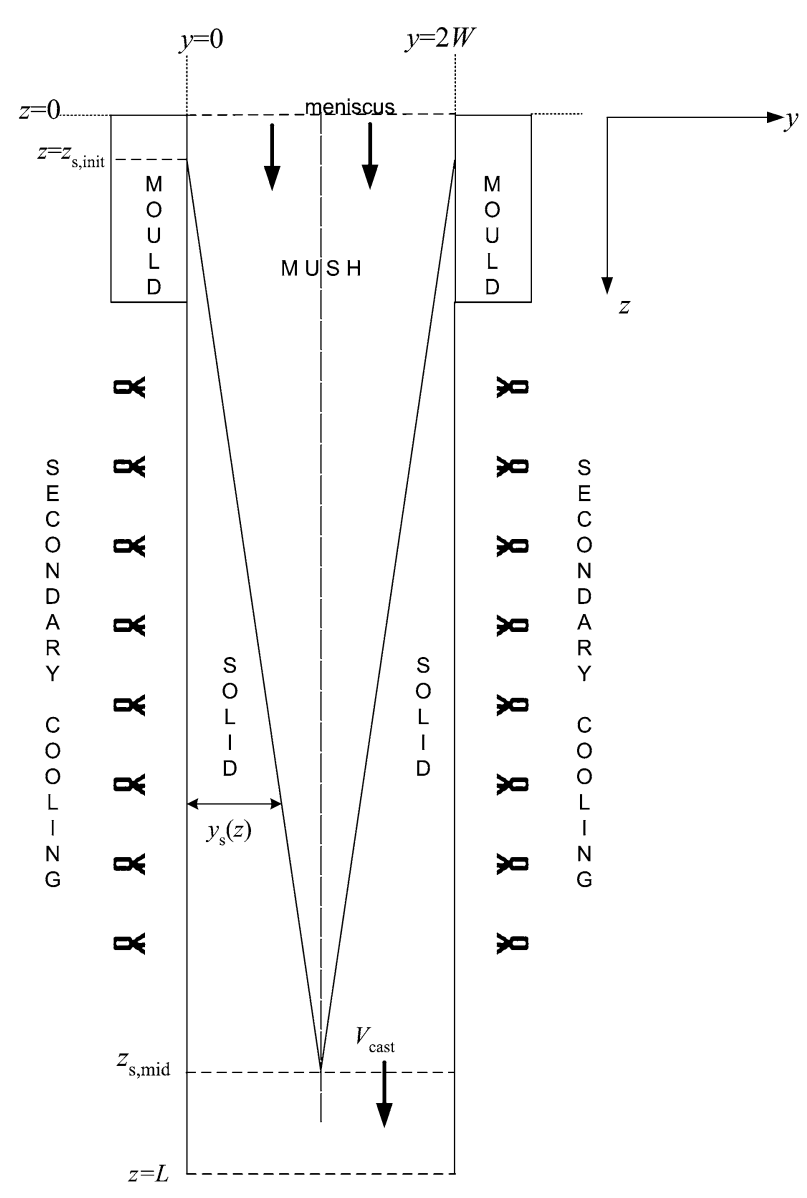

Figure $32 \mathrm{D}$ schematic for the idealized continuous casting of steel

we neglect the curvature of the casting geometry shown in Fig. 1 and simply consider a vertical configuration. Thus, below the mould region, there is assumed to be spray cooling, with complete solidification occurring on the centreline at $y=W$, which is assumed to be an axis of symmetry, at $z=z_{\mathrm{s} \text {, mid }}$; thus, it is only necessary to consider the region $0 \leq y \leq W$ and, overall, the mushy zone occupies $y_{s}(z) \leq y \leq W$. Throughout, the solidified steel is withdrawn with a constant casting speed, $V_{\text {cast }}$.

Here, we avail of the formulation given by Vynnycky et al. [40], which in turn was developed from those given by Ni and Beckermann [25], Reddy and Beckermann [32] and Thevik et al. [38]. We also adopt the following assumptions:

1. the solid phase is rigid and, even in the mushy region, moves downward with the casting speed;

2. the momentum transfer between the liquid and solid phases in the mushy zone is modelled by a Darcy term;

3. there is no formation of gas pores;

4. there is no macroscopic diffusion of solute;

5. there are no dispersive fluxes;

6. all thermophysical properties are constant;

7. the alloy is binary; 
8. thermodynamical equilibrium prevails in the mushy zone, and the liquidus and solidus lines in the thermodynamic phase diagram, which will be discussed shortly, are linear.

Balancing the total mass over solid and liquid phases gives

$$
\nabla \cdot\left(\rho_{1} \chi \mathbf{v}_{\mathrm{l}}+\rho_{\mathrm{s}}(1-\chi) \mathbf{v}_{\mathrm{s}}\right)=0
$$

where $\rho_{1}$ and $\rho_{1}$ are the densities of the liquid and solid phases, respectively, and $\rho$ is the mixture density, which is related to $\rho_{\mathrm{l}}$ and $\rho_{\mathrm{s}}$ by

$$
\rho=\chi \rho_{1}+(1-\chi) \rho_{\mathrm{s}}
$$

where $\chi$ is the liquid fraction. In (2.1), $\mathbf{v}_{\mathrm{l}}$ and $\mathbf{v}_{\mathrm{s}}$ are, respectively, the liquid- and solidphase velocity vectors; for the current $2 \mathrm{D}$ model, we have

$$
\mathbf{v}_{\mathrm{l}}=\left(v_{y}, v_{z}\right), \quad \mathbf{v}_{\mathrm{s}}=\left(0, V_{\text {cast }}\right),
$$

where $v_{y}$ and $v_{z}$ denote the $y$ - and $z$-components of the liquid velocity, respectively.

The momentum balance for the liquid phase is given by

$$
\mu \mathbf{v}=\boldsymbol{\kappa} \cdot\left(-\nabla p+\rho_{\mathbf{l}} \mathbf{g}\right)
$$

where $\mathbf{v}=\chi\left(\mathbf{v}_{\mathrm{l}}-\mathbf{v}_{\mathrm{s}}\right), \mu$ is the dynamic viscosity of the liquid phase, $p$ is the pressure, $\mathbf{g}=$ $(0, g)$ is the gravity vector and $\boldsymbol{\kappa}$ is the permeability tensor for the mushy region. Typically, $\kappa$ is taken to be of the isotropic form $\kappa \mathbf{I}$, where $\mathbf{I}$ is the identity matrix and $\kappa$ is a function of the liquid fraction, given often by the Carman-Kozeny relation as

$$
\kappa(\chi)=\frac{\kappa_{0} \chi^{3}}{(1-\chi)^{2}}
$$

where $\kappa_{0}$ is given in terms of the primary or secondary dendrite arm spacings, $\lambda_{1}$ and $\lambda_{2}$ respectively [7, 17]; examples are

$$
\kappa_{0}=0.0006 \lambda_{1}^{2}, \quad \kappa_{0}=\frac{\lambda_{2}^{2}}{180} .
$$

Although $\boldsymbol{\kappa}$ is sometimes taken to be an orthotropic tensor [24,30], the key quantity here will turn out to be the power, $\sigma$, to which $\chi$ is raised as $\chi \rightarrow 0$; in [24, 30], $\sigma=2$ or $\sigma=3$. For example, Poirier [30] has $\sigma=3$ both parallel and normal to the primary dendrite arms, although $\sigma=2$ parallel and $\sigma=3$ normal to the primary dendrite arms in later work [13, $14,31]$. In our analysis, it will turn out that only $\kappa_{z z}$, i.e. normal to the primary dendrite arms, needs to be used, and we will only use the notation $\kappa$. Nevertheless, it should be noted that most of these results are for columnar dendritic structures, whereas the centre of the steel casting is preferably equiaxed. Note that (2.4), which is in essence Darcy's law, is consistent with the assumption that $T_{\text {cast }}=T_{\text {liq }}$ and that the mushy zone starts at $z=0$; as a consequence, there is no reason to employ the full Navier Stokes equations as part of the momentum balance. The $y$ - and $z$-components of equation (2.4) are then

$$
0=-\frac{\partial p}{\partial y}-\frac{\mu \chi v_{y}}{\kappa(\chi)}
$$




$$
0=-\frac{\partial p}{\partial z}-\frac{\mu \chi\left(v_{z}-V_{\text {cast }}\right)}{\kappa(\chi)}+\rho_{\mathrm{l}} g
$$

respectively.

The equation for the conservation of energy is

$$
\nabla \cdot\left(\chi \rho_{\mathrm{l}} \mathbf{v}_{\mathrm{l}} \mathcal{H}_{\mathrm{l}}+(1-\chi) \rho_{\mathrm{s}} \mathbf{v}_{\mathrm{s}} \mathcal{H}_{\mathrm{s}}\right)=\frac{\partial}{\partial y}\left(k \frac{\partial T}{\partial y}\right)
$$

where $T$ is the temperature, and $k$ is the mixture thermal conductivity, given by

$$
k=\chi k_{1}+(1-\chi) k_{\mathrm{s}}
$$

respectively. In (2.10), $k_{1}$ and $k_{\mathrm{s}}$ are the liquid- and solid-phase thermal conductivities, respectively, both of which will be assumed constant. In (2.9), $\mathcal{H}_{1}$ and $\mathcal{H}_{\mathrm{s}}$ are the liquidand solid-phase enthalpies, respectively, and are given by

$$
\mathcal{H}_{\mathrm{l}}=C_{\mathrm{pl}} T+\Delta H_{\mathrm{f}}, \quad \mathcal{H}_{\mathrm{s}}=C_{\mathrm{ps}} T
$$

where $C_{\mathrm{pl}}$ and $C_{\mathrm{ps}}$ are the respective specific heats for the liquid and solid phases, also assumed constant, and $\Delta H_{\mathrm{f}}$ is the latent heat. Moreover, since the geometry for the continuous casting of steel can be considered slender-the horizontal extent is typically tens of centimetres, whereas the solidification length is around 20 metres-it is reasonable to expect that $\partial^{2} / \partial y^{2} \gg \partial^{2} / \partial z^{2}$; this explains why a term containing second derivatives in $z$ in equation (2.9) has been neglected. So, equation (2.9) becomes, in full form,

$$
\begin{aligned}
& \frac{\partial}{\partial y}\left(\chi \rho_{\mathrm{l}} v_{y} \mathcal{H}_{\mathrm{l}}\right)+\frac{\partial}{\partial z}\left(\chi \rho_{\mathrm{l}} v_{z} \mathcal{H}_{\mathrm{l}}\right)+V_{\text {cast }} \frac{\partial}{\partial z}\left((1-\chi) \rho_{\mathrm{s}} \mathcal{H}_{\mathrm{s}}\right) \\
& =\frac{\partial}{\partial y}\left(\left(\chi k_{1}+(1-\chi) k_{\mathrm{s}}\right) \frac{\partial T}{\partial y}\right) .
\end{aligned}
$$

The form of the equation for the conservation of solute, taken over solid and liquid phases, depends on the assumption made regarding diffusion in the solid at the microscale. Assuming this to be infinitely fast leads to what is often termed the lever rule, namely,

$$
\nabla \cdot\left(\rho_{\mathrm{l}} \chi c_{\mathrm{l}} \mathbf{v}_{\mathrm{l}}+\rho_{\mathrm{s}}(1-\chi) c_{\mathrm{s}} \mathbf{v}_{\mathrm{s}}\right)=0
$$

with $c_{1}$ and $c_{\mathrm{s}}$ as the respective solute concentrations in the liquid and solid phases, which are related by

$$
c_{\mathrm{s}}=k_{0} c_{1} \text {, }
$$

where $k_{0}$ is the partition coefficient; at the other extreme, assuming diffusion in the solid at the microscale to be negligible leads to

$$
\nabla \cdot\left(\chi \rho_{\mathrm{l}} c_{\mathrm{l}} \mathbf{v}_{\mathrm{l}}+\rho_{\mathrm{s}}\left\{\int_{0}^{1-\chi} c_{\mathrm{s}} \mathrm{d} \chi^{\prime}\right\} \mathbf{v}_{\mathrm{s}}\right)=0,
$$


which is often termed the Scheil assumption. (2.13) and (2.15) can be manipulated to give

$$
V_{\text {cast }} \frac{\partial}{\partial z}(\rho c)+\nabla \cdot\left(\rho_{1} c_{1} \mathbf{v}\right)=0,
$$

where $c$ is the mixture concentration, given by

$$
\rho c=\chi \rho_{1} c_{1}+ \begin{cases}\rho_{\mathrm{s}}(1-\chi) c_{\mathrm{s}}, & \text { lever rule } \\ \rho_{\mathrm{s}} \int_{0}^{1-\chi} c_{\mathrm{s}} \mathrm{d} \chi^{\prime}, & \text { Scheil assumption }\end{cases}
$$

For the purposes of generalization, it is possible to introduce a parameter $\alpha$, where $0 \leq$ $\alpha \leq 1$, that allows for a back-diffusion treatment that lies between the limits of zero back diffusion ( $\alpha=0$, the Scheil assumption) and complete back diffusion ( $\alpha=1$, the lever rule); as indicated in [36], this treatment of back diffusion is equivalent to using the Clyne and Kurz correction [5] of the well-known back diffusion model of Brody and Flemings [3]. Following [36] in first setting

$$
\int_{0}^{1-\chi} \frac{\partial c_{\mathrm{s}}}{\partial z} \mathrm{~d} \chi^{\prime}=\alpha(1-\chi) k_{0} \frac{\partial c_{1}}{\partial z}
$$

equation (2.16) becomes, in 2D,

$$
\begin{gathered}
V_{\text {cast }}\left\{\rho_{1} \frac{\partial}{\partial z}\left(\chi c_{1}\right)-k_{0} \rho_{\mathrm{s}} c_{1} \frac{\partial \chi}{\partial z}+\rho_{\mathrm{s}} \alpha(1-\chi) k_{0} \frac{\partial c_{1}}{\partial z}\right\} \\
+\frac{\partial}{\partial y}\left(\rho_{1} c_{1} \chi v_{y}\right)+\frac{\partial}{\partial z}\left(\rho_{1} c_{1} \chi\left(v_{z}-V_{\text {cast }}\right)\right)=0 .
\end{gathered}
$$

We also have local thermodynamic equilibrium in the mushy region, so that

$$
T=T_{\mathrm{m}}-m c_{1} \quad \text { for } 0 \leq \chi \leq 1,
$$

where $T_{\mathrm{m}}$ would typically denote the melting point of the solvent element and $m>0$. In addition, it is evident that $T_{\text {liq }}=T_{\mathrm{m}}-m c_{0}$; thus, we are taking $T_{\text {cast }}=T_{\text {liq. }}$. To maintain connection to the casting of steel, we show the equilibrium phase diagram for the $\mathrm{Fe}-$ $\mathrm{C}$ system in Fig. 4. Note that, for carbon steel, we would have $c_{0} \leq 2.14 \mathrm{wt} \%$, whilst for alloyed steels, significantly more complex phase diagrams need to be considered, although a degree of analytical tractability may still be possible for ternary alloys, such as $\mathrm{Fe}-\mathrm{Mn}-\mathrm{C}$ [23] or Fe-S-C [33]. We will return to discuss Fig. 4 further, and in particular its relation to $\alpha$ in (2.19), in Sect. 2.3 .

\subsection{Boundary conditions}

The boundary conditions for equation (2.9) are

$$
\begin{aligned}
& k \frac{\partial T}{\partial y}=h\left(T-T_{\mathrm{o}}\right) \quad \text { at } y=0, \\
& \frac{\partial T}{\partial y}=0 \quad \text { at } y=W, \\
& T=T_{\text {cast }} \quad \text { at } z=0,
\end{aligned}
$$




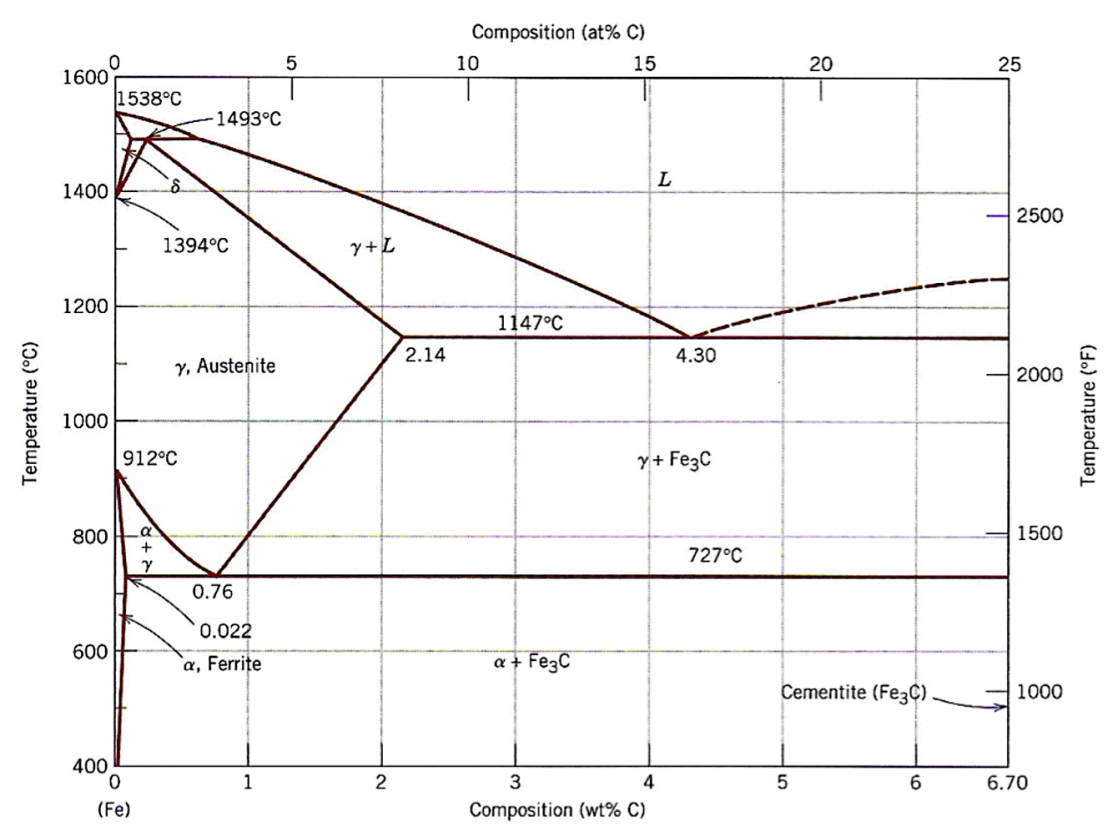

Figure 4 Equilibrium phase diagram for the Fe-C system

where $T_{\mathrm{o}}$ is the cooling temperature and $h$ is the heat transfer coefficient. Equation (2.21) is taken as a generalized form that encompasses cooling in the mould region, as well spray and radiative cooling in the secondary cooling region. Whilst $T_{\mathrm{o}}$ and $h$ are, in general, functions of $z$, we take them for simplicity to be constant; as will become evident later, their exact forms are not of importance for the ongoing analysis or this paper's ultimate conclusions, as regards shrinkage porosity. We also have

$$
\begin{aligned}
& p=p_{a} \quad \text { at } z=0, \\
& v_{z}=\rho_{\mathrm{s}} V_{\text {cast }} / \rho_{\mathrm{l}} \quad \text { at } z=0, \\
& v_{y}=0 \quad \text { at } y=0 \text { and } W, \\
& v_{z}=V_{\text {cast }} \quad \text { at } z=L,
\end{aligned}
$$

where $p_{a}$ is the atmospheric pressure. For $c$, we have

$$
c=c_{0} \quad \text { at } z=0 \text {; }
$$

moreover, as there is no solid there, the above implies that

$$
\chi=1 \quad \text { at } z=0 .
$$

We must also have

$$
\frac{\partial c_{1}}{\partial y}=0 \quad \text { at } y=W
$$


this condition appears to have been omitted in [40], but is consistent with (2.20) and (2.22) and is necessary in light of the forthcoming discussion in Sect. 2.3.

\subsection{Further comments: mush-solid interface}

As in [40], it is convenient to be able to make an explicit distinction between the solid and mush, so as to be able to set conditions at the interface between them. Three conditions are required here; two of these-the continuity of temperature and a heat balance-are straightforward, but the third is less so. It is evident that the temperature on the mush side of this interface must satisfy (2.20), but this in itself does not provide a third condition, since $c_{1}$ is not yet known. However, since (2.28) and (2.30) can be considered as Cauchy data for (2.19), it should mean that $c_{1}$ is computed at $y=y_{\mathrm{s}}(z)$. Hence, we set

$$
T=T_{\mathrm{m}}-m c_{1} \quad \text { at } y=y_{\mathrm{s}}(z)
$$

with the continuity of temperature and a heat balance being given, respectively, by

$$
\begin{aligned}
& {[T]^{+}=0 \quad \text { at } y=y_{\mathrm{s}}(z),} \\
& {\left[k \frac{\partial T}{\partial y}\right]_{-}^{+}=\rho_{\mathrm{s}} \Delta H_{\mathrm{f}} \chi \frac{\mathrm{d} y_{\mathrm{s}}}{\mathrm{d} z} \quad \text { at } y=y_{\mathrm{s}}(z),}
\end{aligned}
$$

with the notation [ $]_{-}^{+}$in (2.32) and (2.33) denoting the difference in the value of a function above and below $y=y_{\mathrm{s}}(z)$, and with the right-hand side in (2.33) containing a latent heat term; see $[2,40]$ for further discussion. It should be noted that this description is not, strictly speaking, valid for a carbon steel in which a peritectic reaction occurs [4, 34], as is the case for the $\mathrm{Fe}-\mathrm{C}$ system at $0.16 \mathrm{wt} \% \mathrm{C}$, meaning that more than one solid phase is precipitated; however, this situation is avoided if $0.51 \mathrm{wt} \%<c_{0}<2.14 \mathrm{wt} \%$. For convenience later on, we refer to the second of these numbers as $k_{0} c_{\text {eut }}$, where $c_{\text {eut }}$ denotes the eutectic composition, i.e. the composition that gives the lowest possible melting temperature over all of the mixing ratios for the involved component species, which can be read off from Fig. 4 as $4.3 \mathrm{wt} \%$.

In addition to (2.31)-(2.33), an initial-like condition is required for $y_{\mathrm{s}}$; this is simply

$$
y_{\mathrm{s}}\left(z_{\mathrm{s}, \text { init }}\right)=0 .
$$

The definitions of all of the symbols can be found in the Table of Nomenclature.

\section{Nondimensionalization}

Next, we nondimensionalize using

$$
\begin{aligned}
& Y=\frac{y}{W}, \quad Z=\frac{z}{L}, \quad V_{Y}=\frac{v_{y}}{V_{\text {cast }} W / L}, \quad V_{Z}=\frac{v_{z}}{V_{\text {cast }}}, \quad P=\frac{p-\rho_{l} g z-p_{a}}{\mu V_{\text {cast }} L / \kappa_{0}}, \\
& \bar{\kappa}=\frac{\kappa}{\kappa_{0}}, \quad \theta=\frac{T-T_{\mathrm{o}}}{T_{\text {cast }}-T_{\mathrm{o}}} .
\end{aligned}
$$

For later use, we also set

$$
Z_{\mathrm{s}, \text { init }}=\frac{z_{\mathrm{s}, \text { init }}}{L}, \quad Z_{\mathrm{s}, \text { mid }}=\frac{z_{\mathrm{s}, \text { mid }}}{L}, \quad \theta_{\mathrm{s}}=\frac{T_{\mathrm{s}}-T_{\mathrm{o}}}{T_{\text {cast }}-T_{\mathrm{o}}},
$$


and $\beta=\rho_{\mathrm{s}} / \rho_{\mathrm{l}}$; a further dimensionless parameter that will be of significance in the model is the solidification shrinkage, $\epsilon$, given by $\epsilon=\beta-1$.

\subsection{Governing equations}

From equation (2.1), we have

$$
\frac{\partial}{\partial Y}\left(\chi V_{Y}\right)+\frac{\partial}{\partial Z}\left(\chi\left(V_{Z}-\beta\right)\right)=0 .
$$

Equations (2.7) and (2.8) give

$$
\begin{aligned}
& 0=-\frac{\partial P}{\partial Y}-\delta^{2} \frac{\chi V_{Y}}{\bar{\kappa}(\chi)}, \\
& 0=-\frac{\partial P}{\partial Z}-\frac{\chi\left(V_{Z}-1\right)}{\bar{\kappa}(\chi)},
\end{aligned}
$$

respectively, where $\delta=W / L$. Equation (2.12) gives

$$
\begin{gathered}
\frac{\partial}{\partial Y}\left(\chi V_{Y}\left(\mathcal{C}\left(\theta+\theta_{\mathrm{o}}\right)+\frac{1}{S t}\right)\right)+\frac{\partial}{\partial Z}\left(\chi V_{Z}\left(\mathcal{C}\left(\theta+\theta_{\mathrm{o}}\right)+\frac{1}{S t}\right)\right) \\
+\beta \frac{\partial}{\partial Z}\left((1-\chi)\left(\theta+\theta_{\mathrm{o}}\right)\right)=\frac{\beta}{P e} \frac{\partial}{\partial Y}\left((\chi \mathcal{K}+(1-\chi)) \frac{\partial \theta}{\partial Y}\right)
\end{gathered}
$$

where

$$
\begin{aligned}
& \mathcal{K}=\frac{k_{\mathrm{l}}}{k_{\mathrm{s}}}, \quad \theta_{\mathrm{o}}=\frac{T_{\mathrm{o}}}{T_{\text {cast }}-T_{\mathrm{o}}}, \quad \mathcal{C}=\frac{C_{\mathrm{pl}}}{C_{\mathrm{ps}}}, \\
& S t=\frac{C_{\mathrm{ps}}\left(T_{\text {cast }}-T_{\mathrm{o}}\right)}{\Delta H_{\mathrm{f}}}, \quad P e=\frac{\rho_{\mathrm{s}} V_{\text {cast }} C_{\mathrm{ps}} W^{2}}{k_{\mathrm{s}} L} ;
\end{aligned}
$$

in particular, $S t$ is the Stefan number and $P e$ is the Péclet number.

Equation (2.19) gives

$$
\frac{\partial}{\partial Y}\left(c_{1} \chi V_{Y}\right)+\frac{\partial}{\partial Z}\left(c_{1} \chi V_{Z}\right)+\beta k_{0}\left\{\alpha(1-\chi) \frac{\partial c_{1}}{\partial Z}-c_{1} \frac{\partial \chi}{\partial Z}\right\}=0 .
$$

Moreover, equation (2.20) gives

$$
\theta=\theta_{\mathrm{m}}-\tilde{m} c_{1} \quad \text { for } 0 \leq \chi \leq 1,
$$

where $\tilde{m}=m /\left(T_{\text {cast }}-T_{\mathrm{o}}\right)$ and $\theta_{\mathrm{m}}=\left(T_{\mathrm{m}}-T_{\mathrm{o}}\right) /\left(T_{\text {cast }}-T_{\mathrm{o}}\right)$, whereas equation (2.14) remains unchanged.

\subsection{Boundary conditions}

Equations (2.21)-(2.28) become, respectively,

$$
\begin{aligned}
& {[(\mathcal{K}-1) \chi+1] \frac{\partial \theta}{\partial Y}=B i \theta \quad \text { at } Y=0,} \\
& \frac{\partial \theta}{\partial Y}=0 \quad \text { at } Y=1,
\end{aligned}
$$




$$
\begin{aligned}
& \theta=0 \quad \text { at } Z=0, \\
& P=0 \quad \text { at } Z=0, \\
& V_{Z}=\beta \quad \text { at } Z=0, \\
& V_{Y}=0 \quad \text { at } Y=0 \text { and } 1, \\
& V_{Z}=1 \quad \text { at } Z=1, \\
& c=c_{0} \quad \text { at } Z=0,
\end{aligned}
$$

where $B i$ is the Biot number, which is given by

$$
B i=\frac{h W}{k_{1}} ;
$$

also, (2.29) becomes

$$
\chi=1 \quad \text { at } Z=0
$$

whereas (2.30) gives

$$
\frac{\partial c_{1}}{\partial Y}=0 \quad \text { at } Y=1 .
$$

Also, equations (2.31)-(2.33) become

$$
\begin{aligned}
& \theta=\theta_{\mathrm{m}}-\tilde{m} c_{1} \quad \text { at } Y=Y_{\mathrm{s}}(Z), \\
& {[\theta]_{-}^{+}=0 \quad \text { at } Y=Y_{\mathrm{s}}(Z),} \\
& {\left[[(\mathcal{K}-1) \chi+1] \frac{\partial \theta}{\partial Y}\right]_{-}^{+}=\frac{P e}{S t} \chi \frac{\mathrm{d} Y_{\mathrm{s}}}{\mathrm{d} Z} \quad \text { at } Y=Y_{\mathrm{s}}(Z),}
\end{aligned}
$$

respectively, whilst (2.34) gives

$$
Y_{\mathrm{s}}\left(Z_{\mathrm{s}, \text { init }}\right)=0
$$

\section{Analysis}

With

$$
\begin{aligned}
& C_{\mathrm{pl}}, C_{\mathrm{ps}} \sim 700 \mathrm{Jkg}^{-1} \mathrm{~K}^{-1}, \quad g \sim 10 \mathrm{~ms}^{-2}, \quad h \sim 10^{3} \mathrm{Wm}^{-2} \mathrm{~K}^{-1} \\
& k_{\mathrm{l}}, k_{\mathrm{s}} \sim 20 \mathrm{Wm}^{-1} \mathrm{~K}^{-1}, \quad k_{0} \sim 0.5, \quad m \sim 90 \mathrm{~K} / \mathrm{wt} \%, \quad L \sim 20 \mathrm{~m}, \quad, \quad T_{\mathrm{o}} \sim 300 \mathrm{~K}, \quad V_{\text {cast }} \sim 0.01 \mathrm{~ms}^{-1}, \\
& p_{a} \sim 10^{5} \mathrm{Nm}^{-2}, \quad T_{\text {cast }} \sim 1700 \mathrm{~K}, \quad T_{0} \sim 10^{-9} \mathrm{~m}^{2}, \quad \mu \sim 0.007 \mathrm{kgm}^{-1} \mathrm{~s}^{-1}, \\
& \Delta H_{\mathrm{f}} \sim 2.2 \times 10^{5} \mathrm{Jkg}^{-1}, \quad \kappa_{0} \sim \mathrm{kgm}^{-3}, \quad \rho_{\mathrm{s}} \sim 7200 \mathrm{kgm}^{-3},
\end{aligned}
$$

which are based on typical characteristic values for the continuous casting of steel [7, 26, 33], we arrive at

$$
B i \sim 5, \quad \mathcal{K} \sim 1, \quad \tilde{m} \sim 0.06, \quad P e \sim 1.3, \quad \text { St } \sim 4.5,
$$




$$
\beta \sim 1.03, \quad \epsilon \sim 0.03, \quad \delta \sim 5 \times 10^{-4}, \quad \mathcal{C} \sim 1, \quad \theta_{\mathrm{o}} \sim 0.2
$$

as the characteristic values for the problem's dimensionless parameters.

Since the main interest here is solidification shrinkage in a slender geometry, it is natural to exploit the fact that $\delta$ and $\epsilon$ are small, with a view to simplifying the problem asymptotically; furthermore, we take all other dimensionless parameters to be nominally $O(1)$.

First of all, we consider the fact that $\epsilon \ll 1$. As in [40], we expect regular asymptotic series expansions for

$$
\phi=\left(V_{Z}, V_{Y}, P, c_{1}, c_{\mathrm{s}}, \chi, \theta\right)
$$

in the form

$$
\phi=\phi^{(0)}+\epsilon \phi^{(1)}+o(\epsilon) .
$$

For later use, we also introduce

$$
Y_{\mathrm{s}}(Z)=Y_{\mathrm{s}}^{(0)}(Z)+\epsilon Y_{\mathrm{s}}^{(1)}(Z)+\cdots
$$

for the location of the solid-mush interface, as well as its inverse function

$$
\mathcal{Z}_{\mathrm{s}}(Y)=\mathcal{Z}_{\mathrm{s}}^{(0)}(Y)+\epsilon \mathcal{Z}_{\mathrm{s}}^{(1)}(Y)+\cdots ;
$$

strictly speaking, the unknowns $Z_{\mathrm{s} \text {,init }}$ and $Z_{\mathrm{s} \text {,mid }}$ should also be expressed as expansions in $\epsilon$, but since we never need any term higher than the leading order, we suppress the ${ }^{()}$ notation for these.

Thence, we consider the governing equations-(3.1)-(3.3), (3.4), (3.6) and (3.7) - and boundary conditions (3.8)-(3.15) at orders $\epsilon^{0}$ and $\epsilon^{1}$. Henceforth, we will set $\mathcal{K}=1, \mathcal{C}=1$, as nothing is gained from the extra generality, but a lot of algebra is spared because of the simplication.

\section{$4.1 \epsilon^{0}$}

\subsubsection{Equations}

So, equation (3.1) gives, at $O(1)$,

$$
\frac{\partial}{\partial Y}\left(\chi^{(0)} V_{Y}^{(0)}\right)+\frac{\partial}{\partial Z}\left(\chi^{(0)}\left(V_{Z}^{(0)}-1\right)\right)=0 .
$$

Equations (3.2) and (3.3) give

$$
\begin{aligned}
& 0=-\frac{\partial P^{(0)}}{\partial Y}-\delta^{2} \frac{\chi^{(0)} V_{Y}^{(0)}}{\bar{\kappa}\left(\chi^{(0)}\right)}, \\
& 0=-\frac{\partial P^{(0)}}{\partial Z}-\frac{\chi^{(0)}\left(V_{Z}^{(0)}-1\right)}{\bar{\kappa}\left(\chi^{(0)}\right)},
\end{aligned}
$$

respectively. Equation (3.4) then gives

$$
\frac{\partial}{\partial Z}\left(\theta^{(0)}+\frac{\chi^{(0)}}{S t}\right)+\frac{\partial}{\partial Y}\left(\theta^{(0)} \chi^{(0)} V_{Y}^{(0)}\right)+\frac{\partial}{\partial Z}\left(\theta^{(0)} \chi^{(0)}\left(V_{Z}^{(0)}-1\right)\right)=\frac{1}{P e} \frac{\partial^{2} \theta^{(0)}}{\partial Y^{2}}
$$


Now, equation (3.6) gives, at $O(1)$,

$$
\frac{\partial}{\partial Y}\left(c_{1}^{(0)} \chi^{(0)} V_{Y}^{(0)}\right)+\frac{\partial}{\partial Z}\left(c_{1}^{(0)} \chi^{(0)} V_{Z}^{(0)}\right)+\alpha k_{0}\left(1-\chi^{(0)}\right) \frac{\partial c_{1}^{(0)}}{\partial Z}-k_{0} c_{1}^{(0)} \frac{\partial \chi^{(0)}}{\partial Z}=0
$$

Also, equation (3.7) gives

$$
\theta^{(0)}=\theta_{\mathrm{m}}-\tilde{m} c_{1}^{(0)}
$$

From (3.8)-(3.15), the boundary conditions are

$$
\begin{aligned}
& \frac{\partial \theta^{(0)}}{\partial Y}=B i \theta^{(0)} \quad \text { at } Y=0, \\
& \frac{\partial \theta^{(0)}}{\partial Y}=0 \quad \text { at } Y=1, \\
& \theta^{(0)}=0 \quad \text { at } Z=0, \\
& P^{(0)}=0 \quad \text { at } Z=0, \\
& V_{Z}^{(0)}=1 \quad \text { at } Z=0, \\
& V_{Y}^{(0)}=0 \quad \text { at } Y=0 \text { and } 1, \\
& V_{Z}^{(0)}=1 \quad \text { at } Z=1, \\
& c_{1}^{(0)}=c_{0} \quad \text { at } Z=0,
\end{aligned}
$$

whilst (3.17) implies that

$$
\chi^{(0)}=1 \quad \text { at } Z=0 \text {, }
$$

whereas (3.18) gives

$$
\frac{\partial c_{1}^{(0)}}{\partial Y}=0 \quad \text { at } Y=1
$$

In addition, (3.19)-(3.21) become

$$
\begin{aligned}
& \theta^{(0)}=\theta_{\mathrm{s}} \\
& {\left[\theta^{(0)}\right]_{-}^{+}=0 \quad \text { at } Y=Y_{\mathrm{s}}^{(0)}(Z),} \\
& {\left[\frac{\partial \theta^{(0)}}{\partial Y}\right]_{-}^{+}=\frac{P e}{S t} \chi^{(0)} \frac{\mathrm{d} Y_{\mathrm{s}}^{(0)}}{\mathrm{d} Z} \quad \text { at } Y=Y_{\mathrm{s}}^{(0)}(Z),}
\end{aligned}
$$

respectively, whilst (3.22) gives

$$
Y_{\mathrm{s}}^{(0)}\left(Z_{\mathrm{s}, \text { init }}\right)=0 \text {. }
$$

\subsubsection{Solution}

Equations (4.5)-(4.7) lead to

$$
V_{Z}^{(0)}=1, \quad V_{Y}^{(0)}=0, \quad P^{(0)}=0,
$$


whence equation (4.8) simplifies to

$$
\frac{\partial}{\partial Z}\left(\theta^{(0)}+\frac{\chi^{(0)}}{S t}\right)=\frac{1}{P e} \frac{\partial^{2} \theta^{(0)}}{\partial Y^{2}},
$$

which is similar to that used in [39]. Equations (4.9) and (4.25) give

$$
\frac{\partial}{\partial Z}\left(c_{1}^{(0)} \chi^{(0)}\right)+\alpha k_{0}\left(1-\chi^{(0)}\right) \frac{\partial c_{1}^{(0)}}{\partial Z}-k_{0} c_{1}^{(0)} \frac{\partial \chi^{(0)}}{\partial Z}=0,
$$

which, on using (4.18), leads to

$$
c_{1}^{(0)}=c_{0}\left(\chi^{(0)}+\alpha k_{0}\left(1-\chi^{(0)}\right)\right)^{\frac{k_{0}-1}{1-\alpha k_{0}}},
$$

and hence

$$
c_{\mathrm{s}}^{(0)}=k_{0} c_{0}\left(\chi^{(0)}+\alpha k_{0}\left(1-\chi^{(0)}\right)\right)^{\frac{k_{0}-1}{1-\alpha k_{0}}} .
$$

If $\alpha=1$, we obtain

$$
c_{1}^{(0)}=\frac{c_{0}}{\chi^{(0)}+k_{0}\left(1-\chi^{(0)}\right)},
$$

which is the expression for the lever rule; if $\alpha=0$,

$$
c_{1}^{(0)}=c_{0}\left(\chi^{(0)}\right)^{k_{0}-1},
$$

which is the same expression as that given by the Scheil equation. Thus, for these two extreme cases, it appears that whatever assumption was made about solidification at the microscale resurfaces at leading order at the macroscale. This observation was already made in [40] for the case $\alpha=1$; however, the whole picture now seems to be more complex than this, even for the case $\alpha=1$. Starting with (4.30) and setting $\chi^{(0)}=0$, we obtain $c_{1}^{(0)}=$ $c_{0} / k_{0}$. However, if $c_{0}>k_{0} c_{\text {eut }}$, we would have already reached the eutectic composition; thus $\chi^{(0)}$ cannot reach zero, but instead some value $\chi_{\text {eut }}$ such that $0<\chi_{\text {eut }}<1$. More generally, for $0 \leq \alpha \leq 1$, we have

$$
c_{\text {eut }}=c_{0}\left(\chi_{\text {eut }}+\alpha k_{0}\left(1-\chi_{\text {eut }}\right)\right)^{\frac{k_{0}-1}{1-\alpha k_{0}}},
$$

whence

$$
\chi_{\text {eut }}=\frac{\left(\frac{c_{\text {eut }}}{c_{0}}\right)^{\frac{1-\alpha k_{0}}{k_{0}-1}}-\alpha k_{0}}{1-\alpha k_{0}} .
$$

Even for $c_{0}<k_{0} c_{\text {eut }}$, there appears to be a further problem. At leading order, we would not expect any macrosegregation at all when solidification is complete, so that $c_{\mathrm{s}}^{(0)}=c_{0}$ across the casting section; however, when setting $\chi^{(0)}=0$ in (4.29), we obtain

$$
c_{\mathrm{s}}^{(0)}=k_{0} c_{0}\left(\alpha k_{0}\right)^{\frac{k_{0}-1}{1-\alpha k_{0}}} \quad \text { at } Y=Y_{\mathrm{s}}^{(0)}(Z)
$$


which only equals $c_{0}$ when $\alpha=1$. The only resolution here, analogous to that for $c_{0}>k_{0} c_{\text {eut }}$, is that $\chi^{(0)}$ decreases to some value $0<\chi_{\mathrm{s}}<1$ such that

$$
k_{0}\left(\chi_{\mathrm{s}}+\alpha k_{0}\left(1-\chi_{\mathrm{s}}\right)\right)^{\frac{k_{0}-1}{1-\alpha k_{0}}}=1
$$

meaning that

$$
\chi_{\mathrm{s}}=\frac{k_{0}^{\frac{1-\alpha k_{0}}{1-k_{0}}}-\alpha k_{0}}{1-\alpha k_{0}}
$$

consequently, we will have just

$$
c_{1}^{(0)}=c_{0} / k_{0} \quad \text { at } Y=Y_{\mathrm{s}}^{(0)}(Z),
$$

as required. On the other hand, if $\alpha=0$, equation (4.32) will prevail. Another important quantity will be $\theta^{(0)}$ at $Y=Y_{\mathrm{s}}^{(0)}(Z)$, which can be constructed from (4.22) and $c_{1}^{(0)}$.

In order to determine the macrosegregation and the possible onset of porosity, it is necessary to consider the model equations at $O(\epsilon)$, as is done next.

$4.2 \epsilon^{1}$

4.2.1 Equations

At $\epsilon^{1}$, equation (3.1) gives

$$
\frac{\partial}{\partial Y}\left(\chi^{(0)} V_{Y}^{(1)}\right)+\frac{\partial}{\partial Z}\left(\chi^{(0)}\left(V_{Z}^{(1)}-1\right)\right)=0 .
$$

Equations (3.2) and (3.3) give

$$
\begin{aligned}
& 0=\frac{\partial P^{(1)}}{\partial Y}-\delta^{2} \frac{\chi^{(0)} V_{Y}^{(1)}}{\bar{\kappa}\left(\chi^{(0)}\right)}, \\
& 0=-\frac{\partial P^{(1)}}{\partial Z}-\frac{\chi^{(0)} V_{Z}^{(1)}}{\bar{\kappa}\left(\chi^{(0)}\right)} .
\end{aligned}
$$

Equation (3.4) gives

$$
\frac{\partial}{\partial Y}\left(\theta^{(0)} \chi^{(0)} V_{Y}^{(1)}\right)+\frac{\partial}{\partial Z}\left(\theta^{(0)} \chi^{(0)}\left(V_{Z}^{(1)}-1\right)+\theta^{(1)}+\frac{\chi^{(1)}}{S t}\right)=\frac{1}{P e} \frac{\partial^{2} \theta^{(1)}}{\partial Y^{2}}
$$

whilst equation (3.6) gives

$$
\begin{aligned}
& \frac{\partial}{\partial Y}\left(c_{1}^{(0)} \chi^{(0)} V_{Y}^{(1)}\right)+\frac{\partial}{\partial Z}\left(c_{1}^{(0)} \chi^{(0)} V_{Z}^{(1)}\right)+\frac{\partial}{\partial Z}\left(\chi^{(0)} c_{1}^{(1)}+\chi^{(1)} c_{1}^{(0)}\right) \\
& -\alpha k_{0}\left\{c_{1}^{(0)} \frac{\partial \chi^{(1)}}{\partial Z}+c_{1}^{(1)} \frac{\partial \chi^{(0)}}{\partial Z}+c_{1}^{(0)} \frac{\partial \chi^{(0)}}{\partial Z}\right\}=0
\end{aligned}
$$

From (3.7), we have

$$
\theta^{(1)}=-\tilde{m} c_{1}^{(1)} .
$$


At this order, equations (3.8)-(3.15) yield

$$
\begin{aligned}
& \frac{\partial \theta^{(1)}}{\partial Y}=B i \theta^{(1)} \quad \text { at } Y=0, \\
& \frac{\partial \theta^{(1)}}{\partial Y}=0 \quad \text { at } Y=1, \\
& \theta^{(1)}=0 \quad \text { at } Z=0, \\
& P^{(1)}=0 \quad \text { at } Z=0, \\
& V_{Z}^{(1)}=1 \quad \text { at } Z=0, \\
& V_{Y}^{(1)}=0 \quad \text { at } Y=0, \\
& V_{Y}^{(1)}=0 \quad \text { at } Y=1, \\
& V_{Z}^{(1)}=0 \quad \text { at } Z=1, \\
& c_{1}^{(1)}=0 \quad \text { at } Z=0,
\end{aligned}
$$

with (3.17) giving

$$
\chi^{(1)}=0 \quad \text { at } Z=0 \text {, }
$$

and (3.18) giving

$$
\frac{\partial c_{1}^{(1)}}{\partial Y}=0 \quad \text { at } Y=1
$$

Also, equations (3.19)-(3.21) at $O(\epsilon)$ give, at $Y=Y_{\mathrm{s}}^{(0)}(Z)$,

$$
\begin{aligned}
& \theta^{(1)}=0, \\
& {\left[\theta^{(1)}\right]_{-}^{+}=0,} \\
& {\left[Y_{\mathrm{s}}^{(1)} \frac{\partial \theta^{(0)}}{\partial Y}+\frac{\partial \theta^{(1)}}{\partial Y}\right]_{-}^{+}=\frac{P e}{S t}\left(\chi^{(0)} \frac{\mathrm{d} Y_{\mathrm{s}}^{(1)}}{\mathrm{d} Z}+\left\{\chi^{(1)}+Y_{\mathrm{s}}^{(1)} \frac{\partial \chi^{(0)}}{\partial Y}\right\} \frac{\mathrm{d} Y_{\mathrm{s}}^{(0)}}{\mathrm{d} Z}\right),}
\end{aligned}
$$

the third of which simplifies to

$$
\left[\frac{\partial \theta^{(1)}}{\partial Y}\right]_{-}^{+}=\frac{P e}{S t}\left(\chi^{(0)} \frac{\mathrm{d} Y_{\mathrm{s}}^{(1)}}{\mathrm{d} Z}+\left\{\chi^{(1)}+Y_{\mathrm{s}}^{(1)}\left(\frac{\partial \chi^{(0)}}{\partial Y}-1\right)\right\} \frac{\mathrm{d} Y_{\mathrm{s}}^{(0)}}{\mathrm{d} Z}\right)
$$

whilst (2.34) gives

$$
Y_{\mathrm{s}}^{(1)}+\frac{\mathrm{d} Y_{\mathrm{s}}^{(0)}}{\mathrm{d} Z}=0 \quad \text { at } Z=Z_{\mathrm{s}, \text { init }}
$$

\subsubsection{Solution}

First, we see that equations (4.35)-(4.37) for $V_{Y}^{(1)}, V_{Z}^{(1)}$ and $P^{(1)}$ decouple from equations (4.38)-(4.40). Cross-differentiating (4.36) and (4.37) so as to eliminate $P^{(1)}$, we have

$$
\delta^{2} \frac{\partial}{\partial Z}\left(\frac{\chi^{(0)} V_{Y}^{(1)}}{\bar{\kappa}\left(\chi^{(0)}\right)}\right)-\frac{\partial}{\partial Y}\left(\frac{\chi^{(0)} V_{Z}^{(1)}}{\bar{\kappa}\left(\chi^{(0)}\right)}\right)=0 .
$$


Now, using the fact that $\delta \ll 1,(4.57)$ reduces to

$$
\frac{\partial}{\partial Y}\left(\frac{\chi^{(0)} V_{Z}^{(1)}}{\bar{\kappa}\left(\chi^{(0)}\right)}\right)=0,
$$

giving

$$
\frac{\chi^{(0)} V_{Z}^{(1)}}{\bar{\kappa}\left(\chi^{(0)}\right)}=f(Z)
$$

where $f$ is a function of $Z$ that has to be determined. In addition, once $f$ is determined, we will have just

$$
\frac{\partial P^{(1)}}{\partial Z}=-f(Z) .
$$

Hence, equations (4.35) and (4.59) should be solved to find $V_{Y}^{(1)}, V_{Z}^{(1)}$ and $P^{(1)}$, with $f(Z)$ being such that boundary conditions (4.45)-(4.48) are satisfied.

$V_{Y}^{(1)}, V_{Z}^{(1)}$ and $P^{(1)}$ are determined in Sect. 4.3, whereas the analysis for determining $\chi^{(1)}$, $c_{1}^{(1)}$ and $\theta^{(1)}$ is presented in Sect. 4.4.

\section{$4.3 V_{Y}^{(1)}, V_{Z}^{(1)}$ and $P^{(1)}$}

The solutions for $V_{Y}^{(1)}, V_{Z}^{(1)}$ and $P^{(1)}$ are exactly the same as those derived in [40], and we simply quote them. We have

$$
\begin{aligned}
& V_{Y}^{(1)}= \begin{cases}\left.\frac{1}{\chi^{(0)}} \int_{0}^{Y} \frac{\partial}{\partial Z}\left(\chi^{(0)}-\chi^{(0)} V_{Z}^{(1)}\right)\right) \mathrm{d} Y^{\prime} & \text { for } 0 \leq Z \leq Z_{\mathrm{s}, \text { init }}, \\
\left.\frac{1}{\chi^{(0)}} \int_{Y_{\mathrm{s}}^{(0)}}^{Y}(Z) \frac{\partial}{\partial Z}\left(\chi^{(0)}-\chi^{(0)} V_{Z}^{(1)}\right)\right) \mathrm{d} Y^{\prime} & \text { for } Z>Z_{\mathrm{s}, \text { init }},\end{cases} \\
& V_{Z}^{(1)}= \begin{cases}\frac{\bar{\kappa}\left(\chi^{(0)}\right)}{\chi^{(0)}} \frac{\int_{0}^{1} \chi^{(0)}\left(Y^{\prime}, Z\right) \mathrm{d} Y^{\prime}}{\int_{0}^{1} \bar{\kappa}\left(\chi^{(0)}\right) \mathrm{d} Y^{\prime}} & \text { for } 0 \leq Z \leq Z_{\mathrm{s}, \text { nit }}, \\
\frac{\bar{\kappa}\left(\chi^{(0)}\right)}{\chi^{(0)}} \frac{\int_{Y_{s}^{(0)}(Z)}^{1} \chi^{(0)}\left(Y^{\prime}, Z\right) \mathrm{d} Y^{\prime}}{\int_{Y_{s}^{(0)}(Z)}^{1} \bar{k}\left(\chi^{(0)}\right) \mathrm{d} Y^{\prime}} & \text { for } Z>Z_{\mathrm{s}, \text { init }}\end{cases} \\
& P^{(1)}=-\int_{0}^{Z} f\left(Z^{\prime}\right) \mathrm{d} Z^{\prime} \text {, }
\end{aligned}
$$

where

$$
f(Z)= \begin{cases}\frac{\int_{0}^{1} \chi^{(0)}\left(Y^{\prime}, Z\right) \mathrm{d} Y^{\prime}}{\int_{0}^{1} \bar{\kappa}\left(\chi^{(0)}\right) \mathrm{d} Y^{\prime}} & \text { for } 0 \leq Z \leq Z_{\mathrm{s}, \text { init }}, \\ \frac{\int_{Y_{\mathrm{s}}^{(0)}(Z)}^{1} \chi^{(0)}\left(Y^{\prime}, Z\right) \mathrm{d} Y^{\prime}}{\int_{Y_{\mathrm{s}}^{1}(Z)}^{1} \bar{\kappa}\left(\chi^{(0)}\right) \mathrm{d} Y^{\prime}} & \text { for } Z>Z_{\mathrm{s}, \text { init }}\end{cases}
$$

In fact, the results at this stage are already enough to infer conclusions regarding the onset of shrinkage porosity. Nevertheless, for completeness, we include the equations that it would be necessary to solve in order to compute the macrosegregation before returning once again to the shrinkage porosity in Sect. 5. 
$4.4 \chi^{(1)}, c_{1}^{(1)}$ and $\theta^{(1)}$

$\chi^{(1)}, c_{1}^{(1)}$ and $\theta^{(1)}$ satisfy (4.38)-(4.40), subject to (4.41)-(4.43), (4.49), (4.53) and (4.55). In particular, equations (4.38) and (4.39) can be rewritten as

$$
\begin{aligned}
& \frac{\partial \theta^{(1)}}{\partial Z}-\frac{1}{S t} \frac{\partial \chi^{(1)}}{\partial Z}-\frac{1}{P e} \frac{\partial^{2} \theta^{(1)}}{\partial Y^{2}}=F_{1}(Y, Z), \\
& \frac{\partial}{\partial Z}\left(\chi^{(0)} c_{1}^{(1)}+\chi^{(1)} c_{1}^{(0)}\right) \\
& \quad-\alpha k_{0}\left\{c_{1}^{(0)} \frac{\partial \chi^{(1)}}{\partial Z}+c_{1}^{(1)} \frac{\partial \chi^{(0)}}{\partial Z}+c_{1}^{(0)} \frac{\partial \chi^{(0)}}{\partial Z}\right\}=F_{2}(Y, Z),
\end{aligned}
$$

respectively, where

$$
\begin{aligned}
& F_{1}(Y, Z)=-\frac{\partial}{\partial Y}\left(\theta^{(0)} \chi^{(0)} V_{Y}^{(1)}\right)-\frac{\partial}{\partial Z}\left(\theta^{(0)} \chi^{(0)}\left(V_{Z}^{(1)}-1\right)\right), \\
& F_{2}(Y, Z)=-\frac{\partial}{\partial Y}\left(c_{1}^{(0)} \chi^{(0)} V_{Y}^{(1)}\right)-\frac{\partial}{\partial Z}\left(c_{1}^{(0)} \chi^{(0)} V_{Z}^{(1)}\right) ;
\end{aligned}
$$

thus, (4.65) and (4.66) are linear partial differential equations for $\theta_{1}^{(1)}$ and $\chi^{(1)}$ that contain right-hand sides, i.e. $F_{1}$ and $F_{2}$ respectively, that would already be known at this stage.

Even so, equations (4.40), (4.65) and (4.66) for $\chi^{(1)}, c_{1}^{(1)}, \theta^{(1)}$ still appear to be strongly coupled, and would need to be solved in order to determine the macrosegregation profile, which is constituted by the solid concentration at $\epsilon^{1}$ at $Y=Y_{\mathrm{s}}^{(0)}(Z)$. To see this, we note first that the actual macrosegregation profile in the solid sample will be $\left.c_{\mathrm{s}}\right|_{Y=Y_{\mathrm{s}}(Z)}$, which can be written in terms of $\left.c_{1}\right|_{Y=Y_{s}(Z)}$ using (2.14). Thence, the two-term Taylor series expansion for $\left.c_{\mathrm{s}}\right|_{Y=Y_{\mathrm{s}}(Z)}$ is

$$
\left.c_{\mathrm{s}}\right|_{Y=Y_{\mathrm{s}}(Z)}=\left.k_{0}\left\{c_{1}^{(0)}+\epsilon\left(c_{1}^{(1)}(Y)+Y_{\mathrm{s}}^{(1)}(Z) \frac{\partial c_{1}^{(0)}}{\partial Y}\right)\right\}\right|_{Y=Y_{\mathrm{s}}^{(0)}(Z)^{+}},
$$

where a plus sign has been introduced in conjunction with the boundary location to indicate the quantity within the parenthesis is being computed from the mush side of the boundary, since $c_{1}$ is not defined on the solid side; observe also that (4.69) is a consequence of the fact that both the dependent variable and the boundary of a domain are functions of an asymptotically small expansion parameter. In view of (4.34), which indicates that $\left.k_{0} c_{1}^{(0)}\right|_{Y=Y_{s}^{(0)}(Z)^{+}}=c_{0}$, i.e. a constant, it is clear that the first term in (4.69) does not given any macrosegregation; instead, the quantity of interest as regards macrosegregation is

$$
\left.\epsilon k_{0}\left(c_{1}^{(1)}(Y)+Y_{\mathrm{s}}^{(1)}(Z) \frac{\partial c_{1}^{(0)}}{\partial Y}\right)\right|_{Y=Y_{\mathrm{s}}^{(0)}(Z)^{+}} .
$$

As shown in [40], for the case when $\alpha=1$, this quantity turns out to be exactly equal to the product of $k_{0}$ and the integral with respect to $Z$ of the right-hand side of (4.66). Since this consists of quantities that are already known by this point, there is no need to compute $\theta_{1}^{(1)}$, $c_{1}^{(1)}, \chi^{(1)}$ and $Y_{\mathrm{s}}^{(1)}$. However, when $\alpha<1$, this is no longer the case, and both the $O(1)$ and $O(\epsilon)$ problems would need to be computed. We do not do this here, but instead return to the issue of shrinkage porosity which is, in any case, independent of the solutions of these equations. 


\section{Results}

As mentioned in Sect. 1, porosity will develop when the pressure decreases below the equilibrium pressure for gas phase, i.e. if ever $p<0$, which is written in dimensionless variables as

$$
P<-\left(\frac{\rho_{l} g L Z+p_{a}}{\mu V_{\text {cast }} L / \kappa_{0}}\right)
$$

or, with the two-term expansion for $P$,

$$
P^{(0)}+\epsilon P^{(1)}<-\left(\frac{\rho_{l} g L Z+p_{a}}{\mu V_{\text {cast }} L / \kappa_{0}}\right) .
$$

Since $P^{(0)}=0$ from (4.25) and since it is evident from (4.63) and (4.64) that $P^{(1)}$ is negative and monotonically decreasing, it is clear that the behaviour of $\chi$ and $\bar{\kappa}$ in (4.64) will determine if (5.2) is ever fulfilled. Moreover, it is evident that the numerator and denominator of $f(Z)$ in (4.64) vanish as the base of the mushy zone is reached, meaning that the actual forms of $\chi$ and $\bar{\kappa}$ will be critical in determining what happens:

- $f \rightarrow \infty$, and hence (5.2) will definitely be satisfied;

- $f$ is finite, and (5.2) is satisfied;

- $f$ is finite, but (5.2) is not satisfied.

The simplest possibility to consider first is when $\chi^{(0)}>0$ at $Y=Y_{\mathrm{s}}^{(0)}(Z)$, in which case

$$
f \rightarrow \frac{\chi_{s}}{\overline{\bar{\kappa}}\left(\chi_{s}\right)} \text {. }
$$

In fact, this appears to occur for the majority of cases, as it corresponds to $0 \leq \alpha<1$ and $c_{0}<k_{0} c_{\text {eut }}$, as well as $0 \leq \alpha \leq 1$ and $k_{0} c_{\text {eut }} \leq c_{0}<c_{\text {eut }}$; ironically, it does not occur for the one considered in [40], for which $\alpha=1$ and $c_{0}<k_{0} c_{\text {eut }}$. The behaviour given in (5.3) corresponds to the second and third of the possibilities listed above. (5.2) is likely to be satisfied the greater the value of $\chi_{s} / \bar{\kappa}\left(\chi_{s}\right)$. If $\bar{\kappa} \sim \chi^{\sigma}$ near $\chi=0$, with $\sigma>0$, we are left considering $\chi_{s}^{1-\sigma}$; from the point of view of avoiding centreline porosity, clearly if $\sigma>1$, larger $\chi_{s}$ is preferable, whereas if $0<\sigma<1$, smaller $\chi_{s}$ would be preferable. Nevertheless, in either case, $P^{(1)}$ remains finite at the centreline as $Y \rightarrow Y_{\mathrm{s}}^{(0)}$, meaning that there is a greater likelihood that (5.2) will be satisfied.

The remaining case is for $\alpha=1$ and $c_{0}<k_{0} c_{\text {eut }}$. In fact, this is arguably of greater significance for the continuous casting of steel: not only is the range for $c_{0}$ is more appropriate, as was mentioned earlier, but also $\alpha=1$, corresponding to the infinitely fast diffusion of solute in the solid is the limit often used for the modelling of microsegregation in the Fe$\mathrm{C}$ system [9]. The significance here is that, unlike in the case when $\alpha<1$, we have that $\chi^{(0)} \rightarrow 0$ as $Y \rightarrow Y_{\mathrm{s}}^{(0)}(Z)$, and consequently $\bar{\kappa} \rightarrow 0$. It is instructive to see what happens with different forms for $\chi$ and $\bar{\kappa}$. Suppose we take the simplest possible form for $\chi$, so that it is symmetric about $Y=1$; this would be

$$
\chi \sim\left(Y^{2}-Y_{\mathrm{s}}^{2}(Z)\right)^{\gamma}, \quad \gamma>0
$$

where we now drop the ${ }^{(0)}$ superscripts on $\chi$ and $Y_{\mathrm{s}}$. In fact, there is no need to assume that the form (5.4) holds for the entire length of the casting, but simply at the very bottom 
of the mush. We have

$$
\begin{aligned}
& \int_{Y_{\mathrm{s}}(Z)}^{1} \chi\left(Y^{\prime}, Z\right) \mathrm{d} Y^{\prime} \sim\left(1-Y_{\mathrm{s}}(Z)\right)^{\gamma+1}, \\
& \int_{Y_{\mathrm{s}}(Z)}^{1} \bar{\kappa}(\chi) \mathrm{d} Y^{\prime} \sim\left(1-Y_{\mathrm{s}}(Z)\right)^{\sigma \gamma+1},
\end{aligned}
$$

so that

$$
\frac{\mathrm{d} P^{(1)}}{\mathrm{d} Z} \sim\left(1-Y_{\mathrm{s}}(Z)\right)^{(1-\sigma) \gamma}
$$

Moreover, since $Y_{\mathrm{s}}(Z) \rightarrow 1$ as $Z \rightarrow Z_{\mathrm{s}, \text { mid }}^{-}$, i.e. with the limit being taken from below, and with symmetry about $Y=1$, so that $Y_{\mathrm{s}}^{\prime}(Z) \rightarrow \infty$, we must have

$$
1-Y_{\mathrm{s}}(Z) \sim\left(Z_{\mathrm{s}, \mathrm{mid}}-Z\right)^{\lambda},
$$

where $0<\lambda<1$. Thus, (5.7) becomes

$$
\frac{\mathrm{d} P^{(1)}}{\mathrm{d} Z} \sim\left(Z_{\mathrm{s}, \text { mid }}-Z\right)^{(1-\sigma) \lambda \gamma}
$$

which then gives

$$
P^{(1)} \sim \begin{cases}-\left(Z_{\mathrm{s}, \text { mid }}-Z\right)^{(1-\sigma) \lambda \gamma+1} & (1-\sigma) \lambda \gamma<-1, \\ -\ln \left(Z_{\mathrm{s}, \text { mid }}-Z\right) & (1-\sigma) \lambda \gamma=-1\end{cases}
$$

if $(1-\sigma) \lambda \gamma>-1$, it is clear that $P^{(1)}$ would be finite. Hence, shrinkage porosity would form if $(1-\sigma) \lambda \gamma+1 \leq 0$, i.e.

$$
(\sigma-1) \lambda \gamma \geq 1
$$

Clearly, the greater $\sigma$ is, the greater the likelihood of porosity. Furthermore, from earlier work [39] (see appendix $C$ therein), it can be inferred that $\lambda=1 / 2$, reducing (5.11) to

$$
(\sigma-1) \gamma \geq 2
$$

It is perhaps not entirely clear what the actual value of $\gamma$ is, although there are strong grounds for believing that simply $\gamma=1$, as follows. Clearly, the heat flux across $\chi=0$ is finite and non-zero, so we would have

$$
\theta \approx \theta_{\mathrm{s}}+Q(s) n,
$$

where $n$ is the variable normal to $\chi=0$, which coincides with $n=0$, and

$$
Q:=\left(\frac{\partial \theta}{\partial n}\right)_{n=0}
$$


which is a function of the arc length $s$ along $\chi=0$. Since the analysis already shows that $\chi$ follows the lever rule, we will find that

$$
\chi \approx Q(s) n,
$$

and since $n \sim Y_{\mathrm{s}}(Z)-Y$, we will have

$$
\chi \sim Q(s)\left(Y-Y_{\mathrm{s}}(Z)\right)
$$

so that $\gamma=1$. Thus, with $\gamma=1, \lambda=1 / 2,(5.10)$ becomes

$$
P^{(1)} \sim\left\{\begin{array}{ll}
-\left(Z_{\mathrm{s}, \mathrm{mid}}-Z\right)^{\frac{1}{2}(1-\sigma)+1}, & \sigma>3, \\
\ln \left(Z_{\mathrm{s}, \text { mid }}-Z\right), & \sigma=3
\end{array} \quad \text { as } Z \rightarrow Z_{\mathrm{s}, \text { mid }}^{-} .\right.
$$

For the usual Carman-Kozeny relation, $\sigma=3$, so that $P^{(1)}$ has a logarithmic singularity as $Z \rightarrow Z_{\mathrm{s}, \mathrm{mid}}$, which indicates that the pressure will indeed approach zero and that shrinkage porosity will form; if $\sigma>3$, the singularity is algebraic and the likelihood of porosity even more extreme. A mathematical interpretation of this is that the regular perturbation series for $P$ is no longer well-ordered as $Z \rightarrow Z_{\mathrm{s} \text {,mid. }}$ On the other hand, if $\sigma=2$, which is a case that has also been popularized [1, 21-23, 29, 42], there is no singularity at all.

\section{Discussion}

Although the original model included many physical features, it has turned out that it was possible to treat these hierarchically, leading to a logical, and initially unobvious, link between the model parameters and the phenomena of macrosegregation and shrinkage porosity:

- the key parameters are initial solute concentration $\left(c_{0}\right)$, the solidification shrinkage parameter $(\epsilon)$, the microsegregation parameter $(\alpha)$, and the expression used to relate the permeability of the mush to the liquid fraction, $\chi$-in particular the power, $\sigma$, to which $\chi$ is raised;

- the fact that $\epsilon$ is small means that we can make progress by considering a regular perturbation about $\epsilon=0$;

- the values of $c_{0}$ and $\alpha$ chosen determine whether $\chi \rightarrow 0$ in the mush as complete solidification is reached;

- if $\chi \rightarrow 0$, it is more likely that centreline porosity is formed, since the pressure tends to zero, if $\sigma \geq 3$;

- if $\sigma<3$, the pressure will not tend to zero and it is less likely that centreline porosity is formed;

- if $\chi$ does not tend to zero, it is less likely that centreline porosity is formed;

- the macrosegregation and porosity problems decouple from each other, although both depend on the $O(\epsilon)$ velocities and pressure.

Figure 5 shows a qualitative schematic, ostensibly for $\sigma>3$ in view of the above discussion, showing the relationship of $c_{0}$ and $\alpha$ to the likelihood that centreline porosity is formed. From this, we see that porosity is more likely for higher values of $\alpha$, corresponding to lever-rule solidification at the microscale, and smaller values of $c_{0}$. 


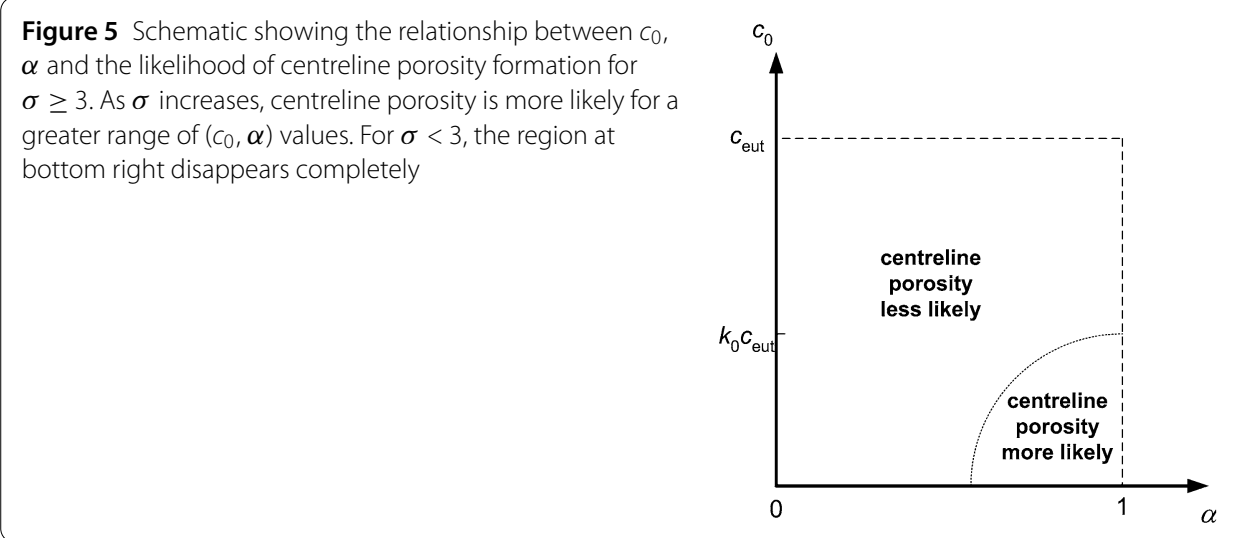

A further question is then whether it might be possible to control or prevent the formation of centreline porosity. One may imagine that controlling $\alpha$, which has to with processes on the microscale, is impossible from the physical point of view; choosing a value of $c_{0}$ closer to $c_{\text {eut }}$ may be impractical from the technological point of view. This leads to the question whether it might be possible to control $\sigma$; this may certainly be easier in a laboratory experiment than in the final solidification zone of a continuous casting machine. Nevertheless, it is necessary to emphasize that, at this stage, the purpose of this investigation has been to give qualitative information on the expected behaviour of a full model based in computational fluid dynamics, as might normally be undertaken by material scientists and engineers [8], rather than to seek to control centreline porosity per se.

Another issue is whether it would be possible to validate these findings in practice. Not all steel alloys that are cast industrially are binary, and often have more components than the two ternary alloys, $\mathrm{Fe}-\mathrm{Mn}-\mathrm{C}$ or $\mathrm{Fe}-\mathrm{S}-\mathrm{C}$, mentioned earlier. In such cases, it is necessary to make use of software tools, such as the TCAL2 database [37], to generating the relevant multicomponent phase diagram, although even this can be unreliable as the number of components is increased. Ultimately perhaps, the greatest likelihood of experimental validation in an industrial setting may be through using the two industrially relevant ternary alloys just mentioned, but extending the current model to include a third component.

\section{Conclusions}

This paper has extended a recent asymptotic model for the solidification shrinkageinduced macrosegregation in the continuous casting of binary alloys for the purposes of understanding the link between solute segregation and centreline shrinkage porosity in the continuous casting of steel. In particular, the analysis has elucidated, in a quite systematic way, the relationship between microsegregation, mushy-zone permeability, heat transfer and centreline pressure; the end result was an inequality, (5.1), that constitutes a criterion for whether centreline porosity will form or not. Furthermore, lever rule diffusion at the microscale, together with a mush permeability that varies as the third power, or greater, of the liquid fraction, $\chi$, for small $\chi$, increases the likelihood of centreline porosity. Although this work has predominantly relied on analysis rather than numerical computations, it does nevertheless provide a framework for the latter; indeed, carrying out computations in the absence of any framework would lead to difficulty in interpreting any 
numerical results, in view of the subtle dependency of the results on $\alpha, \epsilon, \sigma$ and $c_{0}$. Moreover, the analysis presented here can constitute the starting point of a model that includes mechanical soft reduction; mathematically, this will mean that $v_{y}>0$ at $y=0$ in equation (2.26), the effect of which should be to mitigate the singularities encountered in (5.13) or, if there are no singularities, to at least ensure that (5.1) is never satisfied.

Whilst the focus here was on shrinkage porosity, an asymptotic approach may also prove suitable for the modelling of the onset of centreline porosity due to gas rejection or solid deformation-situations which are also both characterized by a surfeit of interacting model parameters.

\section{Nomenclature}

Bi Biot number, $h W / k_{1}$

$c$ solute mixture concentration, [wt\%]

$\mathcal{C}$ dimensionless constant, $C_{\mathrm{pl}} / C_{\mathrm{ps}}$

$c_{0}$ solute composition of alloy at inlet, [wt\%]

$c_{\text {eut }}$ eutectic concentration, [wt\%]

$C_{\mathrm{pl}}$ liquid-phase specific heat capacity, $\left[\mathrm{Jkg}^{-1} \mathrm{~K}^{-1}\right]$

$C_{\mathrm{ps}}$ solid-phase specific heat capacity, $\left[\mathrm{Jkg}^{-1} \mathrm{~K}^{-1}\right]$

$c_{1}$ solute concentration in the liquid phase, [wt\%]

$c_{\mathrm{s}}$ solute concentration in the solid phase, [wt\%]

$f$ function of $Z$ defined in equation (4.64)

$g$ gravitational acceleration, $\left[\mathrm{ms}^{-2}\right]$

g gravity vector, $(0, g),\left[\mathrm{ms}^{-2}\right]$

$h$ heat transfer coefficient, $\left[\mathrm{Wm}^{-2} \mathrm{~K}^{-1}\right.$ ]

$\mathcal{H}_{l}$ liquid-phase enthalpy

$\mathcal{H}_{s}$ solid-phase enthalpy

$k$ mixture thermal conductivity, [ $\left[\mathrm{Wm}^{-1} \mathrm{~K}^{-1}\right.$ ]

$\mathcal{K}$ dimensionless constant, $k_{1} / k_{\mathrm{s}}$

$k_{0}$ partition coefficient

$k_{1}$ liquid-phase thermal conductivity, $\left[\mathrm{Wm}^{-1} \mathrm{~K}^{-1}\right.$ ]

$k_{\mathrm{s}}$ solid-phase thermal conductivity, $\left[\mathrm{Wm}^{-1} \mathrm{~K}^{-1}\right.$ ]

$L$ length scale in $z$-direction for complete solidification, [m]

$m$ slope of the liquid line in the phase diagram, $\left[\mathrm{Kwt}^{-1}{ }^{-1}\right.$

$\widetilde{m}$ dimensionless constant, $m /\left(T_{\text {cast }}-T_{\mathrm{o}}\right)$

$p$ pressure, $[\mathrm{Pa}]$

$P$ dimensionless pressure

$p_{a}$ atmospheric pressure, $[\mathrm{Pa}]$

Pe Péclet number, $\rho_{\mathrm{s}} V_{\text {cast }} C_{\mathrm{ps}} W^{2} / k_{\mathrm{s}} L$

St Stefan number, $C_{\mathrm{ps}}\left(T_{\text {cast }}-T_{\mathrm{o}}\right) / \Delta H_{\mathrm{f}}$

$T$ temperature, $[\mathrm{K}]$

$T_{\mathrm{o}}$ cooling temperature, $[\mathrm{K}]$

$T_{\text {cast }}$ casting temperature, $[\mathrm{K}]$

$T_{\text {liq }}$ liquidus temperature, [K]

$T_{\mathrm{m}}$ melting temperature of pure solvent, [K]

$T_{\text {sol }}$ solidus temperature, $[\mathrm{K}]$

$\mathbf{v}$ relative velocity vector between solid and liquid phases, $\chi\left(\mathbf{v}_{\mathrm{l}}-\mathbf{v}_{\mathrm{s}}\right),\left[\mathrm{ms}^{-1}\right]$ 


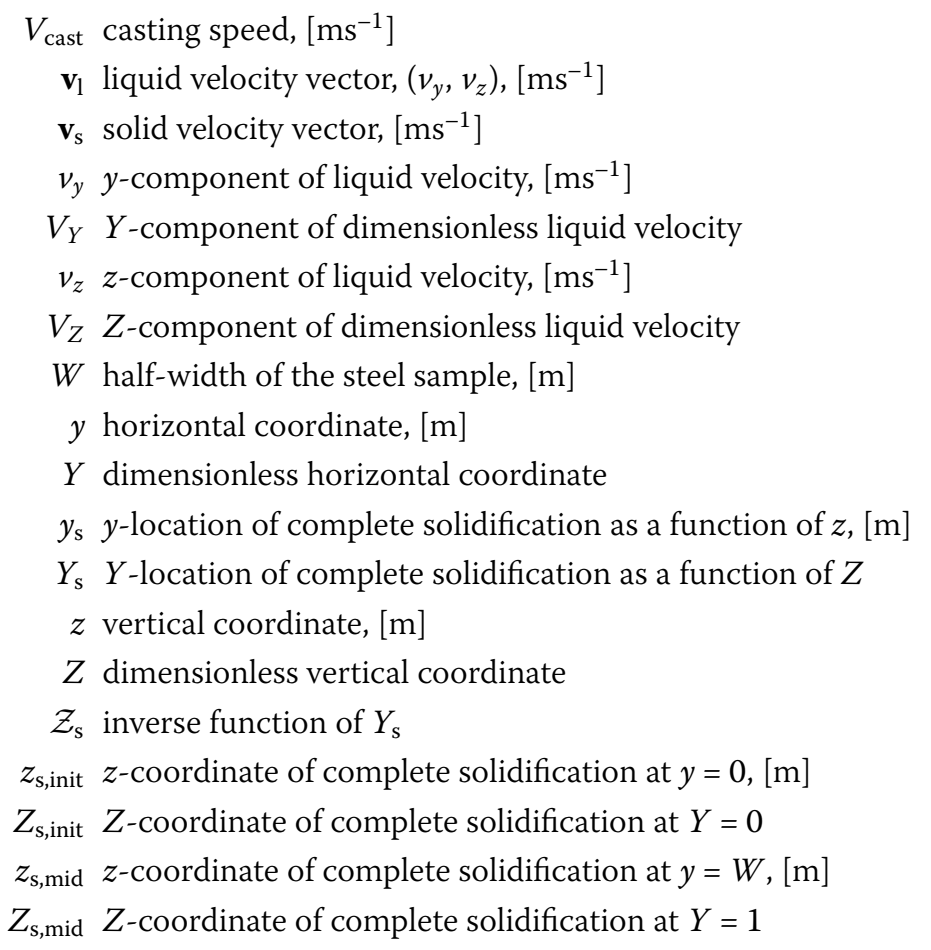

\section{Greek symbols}

$\alpha$ back diffusion parameter

$\beta$ density ratio, $\rho_{\mathrm{s}} / \rho_{\mathrm{l}}$

$\gamma$ dimensionless constant introduced in equation (5.4)

$\delta$ casting geometry aspect ratio, $W / L$

$\Delta H_{\mathrm{f}}$ latent heat, $\left[\mathrm{Jkg}^{-1}\right]$

$\epsilon$ solidification shrinkage parameter, $\beta-1$

$\theta$ dimensionless temperature

$\theta_{\mathrm{m}}$ dimensionless constant, $\left(T_{\mathrm{m}}-T_{\mathrm{o}}\right) /\left(T_{\text {cast }}-T_{\mathrm{o}}\right)$

$\theta_{\mathrm{o}}$ dimensionless cooling temperature, $T_{\mathrm{o}} /\left(T_{\text {cast }}-T_{\mathrm{o}}\right)$

$\kappa$ isotropic permeability function for the mushy region as a function of $\chi,\left[\mathrm{m}^{2}\right]$

$\boldsymbol{\kappa}$ permeability tensor for the mushy region, $\left[\mathrm{m}^{2}\right]$

$\bar{\kappa}$ dimensionless permeability function

$\kappa_{0}$ permeability constant in equation $(2.5),\left[\mathrm{m}^{2}\right]$

$\lambda$ dimensionless constant introduced in equation (5.8)

$\mu$ dynamic viscosity of the liquid phase, $\left[\mathrm{kg} \mathrm{m}^{-1} \mathrm{~s}^{-1}\right]$

$\rho_{1}$ density of alloy in liquid phase, $\left[\mathrm{kgm}^{-3}\right]$

$\rho_{\mathrm{s}}$ density of alloy in solid phase, $\left[\mathrm{kgm}^{-3}\right]$

$\sigma$ dimensionless constant first discussed after equation (2.6)

$\chi$ liquid fraction

$\chi_{\mathrm{s}}$ liquid fraction at $y=y_{\mathrm{s}}(z)$

\section{Acknowledgements}

The author acknowledges useful discussions with Dr. B. Rogberg. 
Abbreviations

Fe-C, iron-carbon; Fe-Mn-C, iron-manganese-carbon; Fe-S-C, iron-sulphur-carbon; TCAL, Thermocalc.

\section{Availability of data and materials}

Data and material are available from the author on request.

Ethics approval and consent to participate

Not applicable.

\section{Competing interests}

The author has no competing interests.

\section{Consent for publication}

Not applicable.

\section{Authors' contributions}

The sole author performed all of the work. The author read and approved the final manuscript.

\section{Publisher's Note}

Springer Nature remains neutral with regard to jurisdictional claims in published maps and institutional affiliations.

Received: 18 June 2019 Accepted: 13 May 2020 Published online: 24 May 2020

\section{References}

1. Amberg G. Computation of macrosegregation in an iron carbon cast. Int J Heat Mass Transf. 1991:34:217-27.

2. Assunção M, Vynnycky M, Mitchell SL. On small-time similarity-solution behaviour in the solidification shrinkage of binary alloys. Eur J Appl Math. 2020. https://doi.org/10.1017/S0956792520000091. Accepted.

3. Brody HB, Flemings MC. Solute redistribution in dendritic solidification. Trans AIME. 1966;236:615-24.

4. Chung JD, Yoo HS. Similarity solution for peritectic solidification with shrinkage-induced flow. J Thermophys Heat Transf. 2003;17:481-7.

5. Clyne TW, Kurz W. Solute redistribution during solidification with rapid solid-state diffusion. Metall Trans A. 1981:12:965-71.

6. Dantzig JA, Rappaz M. Solidification. Lausanne: EPFL Press; 2009.

7. Domitner J, Wu M, Kharicha A, Ludwig A, Kaufmann B, Reiter J, Schaden T. Modeling the effects of strand surface bulging and mechanical softreduction on the macrosegregation formation in steel continuous casting. Metall Mater Trans A. 2014;45A:1415-34.

8. Du P. Numerical modeling of porosity and macrosegregation in continuous casting of steel [PhD thesis]. University of lowa; 2013.

9. Fredriksson H, Åkerlind U. Materials processing during casting. New York: Wiley; 2006.

10. Gao Z, Jie W, Liu Y, Luo H. Solidification modelling for coupling prediction of porosity and segregation. Acta Mater. 2017;127:277-86.

11. Gao Z, Jie W, Liu Y, Luo H. Formation mechanism and coupling prediction of microporosity and inverse segregation: a review. Acta Metall Sin. 2018:54:717-26.

12. Hansen PN, Sahm PR. How to model and simulate the feeding process in casting to predict shrinkage and porosity formation. In: Modeling of casting, welding and advanced solidification processes IV. Warrendale: TMS-AIME; 1988. p. 33.

13. Heinrich JC, Poirier DR. Convection modeling in directional solidification. C R Mecanique. 2004;332:429-45.

14. Heinrich JC, Poirier DR, Nagelhout DF. Mesh generation and flow calculations in highly contorted geometries. Comput Methods Appl Mech Eng. 1996;133:79-92.

15. Jacobi HF. Investigation of centreline segregation and centreline porosity in CC slabs. Steel Res Int 2003;74:667-78.

16. Jones DRH, Ashby MF. Engineering materials 2: an introduction to microstructures, processing, and design. 2 nd ed. Stoneham: Butterworth-Heinemann; 1998.

17. Khalajzadeh V, Carlson KD, Backman DG, Beckermann C. A pore-centric model for combined shrinkage and gas porosity in alloy solidification. Metall Mater Trans A. 2017;48A:1797-816.

18. Kubo K, Pehlke RD. Mathematical modeling of porosity formation in solidification. Metall Trans B. 1985;16:359-66.

19. Lee PD, Chirazi A, See D. Modeling microporosity in aluminum-silicon alloys: a review. J Light Metals. 2001;1:15-30.

20. Lee YW, Chang E, Chieu CF. Modeling of feeding-behavior of solidifying Al-7Si-0.3Mg alloy plate casting. Metall Mater Trans B. 1990;21:715-22.

21. Maples AL, Poirier DR. Convection in the 2-phase zone of solidifying alloys. Metall Trans B. 1984;15:163-72.

22. Mehrabian R, Keane M, Flemings MC. Interdendritic fluid flow and influence of gravity macrosegregation. Metall Trans. 1970:1:1209-20.

23. Miyazawa K, Schwerdtfeger K. Macrosegregation in continuously cast slabs: preliminary theoretical investigation on the effect of steady state bulging. Arch Eisenhüttenwes. 1981;52:415-22.

24. Natsume Y, Takahashi D, Kawashima K, Tanigawa E, Ohsasa K. Quantitative model to determine permeability for columnar dendritic structures. ISIJ Int. 2013;53:838-47.

25. Ni J, Beckermann C. A volume-averaged two-phase model for transport phenomena during solidification. Metall Mater Trans B. 1991;22B:349-61.

26. Nick AS, Vynnycky M, Fredriksson $\mathrm{H}$. A theoretical analysis of the interaction between pores and inclusions during the continuous casting of steel. Metall Mater Trans A. 2016;47A:2985-99.

27. Niyama E, Uchida T, Morikawa M, Saito S. Predicting shrinkage in large steel castings from temperature-gradient calculations. Int Cast Met J. 1981;6:16-22. 
28. Niyama E, Uchida T, Morikawa M, Saito S. A method of shrinkage prediction and its application to steel casting practice. Int Cast Met J. 1982;7:52-63.

29. Piwonka TS, Flemings MC. Pore formation in solidification. Trans Metall Soc AIME. 1966;236:1157-65.

30. Poirier DR. Permeability for flow of interdendritic liquid in columnar-dendritic alloys. Metall Trans B. 1987;18:245-55

31. Poirier DR, Heinrich JC. Continuum model for predicting macrosegregation in dendritic alloys. Mater Charact. 1994:32:287-98.

32. Reddy AV, Beckermann C. Modeling of macrosegregation due to thermosolutal convection and contraction-driven flow in direct chill continuous casting of an Al-Cu round ingot. Metall Mater Trans B. 1997;28B:479-89.

33. Rogberg B, Ek L. Influence of soft reduction on the fluid flow, porosity and center segregation in CC high carbon- and stainless steel blooms. ISIJ Int. 2018;58:478-87.

34. Saleem $S$, Vynnycky M, Fredriksson $H$. The influence of peritectic reaction/transformation on crack susceptibility in the continuous casting of steels. Metall Mater Trans B. 2017;48B:1625-35.

35. Stefanescu DM. Computer simulation of shrinkage related defects in metal castings - a review. Int J Cast Met Res. 2005;18:129-43.

36. Swaminathan CR, Voller VR. Towards a general numerical scheme for solidification systems. Int J Heat Mass Transf. 1997;40:2859-68

37. Thermo-Calc Software TCAL version 2

38. Thevik HJ, Mo A, Rusten T. A mathematical model for surface segregation in aluminum direct chill casting. Metall Mater Trans B. 1999;39B:135-42.

39. Vynnycky M, Saleem S. On the explicit resolution of the mushy zone in the modelling of the continuous casting of alloys. Appl Math Model. 2017;50:544-68.

40. Vynnycky M, Saleem S, Fredriksson H. An asymptotic approach to solidification shrinkage-induced macrosegregation in the continuous casting of binary alloys. Appl Math Model. 2018;54:605-26.

41. Weimer HE, Jacobi H, Wunnenberg K. Influence of solidification structure and casting speed on the center porosity of different steels. Stahl Eisen. 1995;115:67-76.

42. West R. On the permeability of the 2-phase zone during solidification of alloys. Metall Trans A. 1985;16:693.

43. Wu M, Domitner J, Ludwig A. Using a two-phase columnar solidification model to study the principle of mechanical soft reduction in slab casting. Metall Mater Trans A. 2012;43A:945-64.

\section{Submit your manuscript to a SpringerOpen ${ }^{0}$ journal and benefit from:}

- Convenient online submission

- Rigorous peer review

Open access: articles freely available online

- High visibility within the field

- Retaining the copyright to your article

Submit your next manuscript at $>$ springeropen.com 